\title{
POBREZA NOS ESTADOS UNIDOS: DEBATES INTELECTUAIS ${ }^{1}$
}

\author{
Poverty in the United States: intellectual debates
}

\section{Barbara Maria de Albuquerque Mitchell*}

Resumo: $\mathrm{O}$ presente artigo tem como objetivo discutir as diferentes ideias de pobreza nos Estados Unidos. Com foco no século XX, procura-se destacar a pluralidade de visões sobre o tema entre os círculos intelectuais, bem como as influências de tais debates na criação de políticas públicas americanas.

Palavras-chave: Pobreza, Estados Unidos, Intelectuais

Abstract: This article aims to discuss the different ideas of poverty in the United States. Focusing on the $20^{\text {th }}$ century, the intention is to highlight the plurality of visions on the subject among intellectuals, as well as demonstrate the influence of those debates over American public policies.

Keywords: Poverty, United States, Intellectuals

\section{Introdução}

O objetivo deste artigo é discutir algumas das principais concepções de pobreza na década de 1960. Nosso foco será naquelas que circularam no campo intelectual e desembocaram no campo político entre os governo de John F. Kennedy (JFK) e Lyndon B. Johnson (LBJ). O lançamento da Guerra à Pobreza no governo LBJ, marcou uma tentativa de reduzir o problema nos Estados Unidos. O projeto pretendia ampliar as oportunidades para os mais pobres através de programas de treinamento, educação e participação comunitária direta. Contudo, uma das principais dificuldades encontradas pelo Office of Economic Opportunity, agência criada para comandar a iniciativa, foi a de elaborar um plano homogêneo, que deixasse claro qual a visão de pobreza da administração e, por consequência, a melhor maneira de solucioná-la.

A pluralidade de perspectivas marcou, e ainda marca, o debate sobre o tema nos Estados Unidos. A compreensão de quem eram os necessitados, de que modo os classificar e de quais maneiras entender as origens e desdobramentos da sua condição, deram origem a um extenso número de trabalhos. Por isso, acreditamos ser possível pensar mais em "pobrezas" do que em "uma pobreza". A definição exata do termo não é o objetivo, mas sim explorar algumas das principais caracterizações desenvolvidas por intelectuais americanos. Em especial, a promoção do debate permite melhor identificar de que maneira as diferentes concepções do conceito influenciaram as políticas públicas.

Em 1963 o governo americano criou a linha oficial da pobreza. A base do cálculo se fazia a partir da capacidade de compra de alimentos por cada família. Com isso, foram definidos como

\footnotetext{
1 Pesquisa financiada pelo CNPq.

* Pesquisadora na Rede de Estudos de Estados Unidos. Doutoranda em História pelo Programa de Pós-Graduação em História Social da Universidade Federal do Rio de Janeiro (PPGHIS/UFRJ) com Doutorado Sanduíche na Harvard University(2018-2019).ORCID: http://orcid.org/0000-0002-5787-8573 E-mail: barbaram.mitchell@gmail.com
} 
pobres as famílias com quatro membros, que tivessem uma renda inferior à três mil dólares anuais, uma média de $1 / 5$ da população em 1964. Esses números, no entanto, são divergentes aos levantados na época por intelectuais como John K. Galbraith e Gabriel Kolko, assim como pelo Bureau of Labor Statistics (PATTERSON, 2000). Apesar de não ser unânime, o modelo recém-definido na presidência de JFK foi utilizado como base para boa parte das políticas criadas pela Guerra à Pobreza, e se mantém até os dias atuais ${ }^{2}$. Era grande a complexidade de materializar quem seria uma pessoa pobre, assim como quais eram as necessidades entendidas como básicas por diversos grupos da sociedade. Ademais, essas mesmas necessidades eram variáveis geograficamente e temporalmente. Por isso, é necessário manter em mente que a porcentagem de pessoas em situação de pobreza nos EUA variava de acordo com a fonte apontada, ainda que em um mesmo ano, ou local.

Já a variação na composição da população necessitada é um dado bastante importante para pensar o problema no século XX. Existe uma certa constância de mães solteiras, idosos ${ }^{3}$ (PETERSON, 1992,p.621) e minorias, como afro-americanos e nativo-americanos, entre os desproporcionalmente representados (MINK, Gwendolyn; O’CONNOR, Alice, 2004, p.59). Apesar disso, é interessante perceber como os governos e instituições privadas elaboraram propostas extremamente diversas para solucionar a questão ao longo dos anos. Dessa maneira, os múltiplos sentidos atribuídos à pobreza são diretamente relacionados à variedade de supostas soluções. Em estudo dedicado ao welfare americano, Michael Katz defendeu uma polarização histórica entre os chamados deserving, merecedores de auxílio social, e undeserving poors, não-merecedores desse mesmo auxílio (KATZ, 2013). Enquanto o primeiro seria conectado aos grupos que estão em situação de pobreza como consequência de infortúnios: como viúvas, doentes ou acidentados; o último abrangeria todos aqueles vistos como vadios, baderneiros ou preguiçosos. Uma visão tão genérica dos membros da sociedade possibilitou classificações arbitrárias e conectadas aos preconceitos sociais e econômicos vigentes, facilitando a culpabilização daqueles que sofriam pelas suas condições.

A tese de Katz auxilia a compreensão de ideias que permearam, em diferentes níveis, os modos com que a questão foi enxergada e abordada no país. A individualização da situação impulsiou a criação de diferentes estereótipos, que passaram do homem alcóolatra, para os imigrantes europeus não-anglo-saxões e, finalmente, para as black welfare mothers (KATZ, 2013, Posição 2). O darwinismo social e a eugenia, nos séculos XIX e XX, mobilizaram os estudos de Charles Darwin para as constituições sociais e, aliados às teorias raciais, fomentaram perspectivas racistas de interpretação da sociedade e a sua suposta evolução. Nesse sentido, comparando as "evoluções" dos povos mundiais em parâmetros brancos e europeus, passou-se a defender os brancos europeus anglo-saxões, assim como seus descendentes, eram mais evoluídos do que os europeus latinos e do Leste, asiáticos, africanos e latino-americanos.

Essa constituição de uma brancura específica, associada à descendência anglo-saxã, é fundamental, inclusive, para entender a estrutura de privilégios institucionalizados entre os brancos nos Estados Unidos. Internamente, não demorou até que as concepções darwinistas e as teorias raciais fossem utilizadas para justificar a situação de pobreza experimentada por afro-americanos, mulheres, asiáticos, latinos e nativos-americanos. O ambiente de expansão econômica era

\footnotetext{
${ }^{2}$ Em 2010 foi introduzido um Supplemental Poverty Measure ao Official Poverty Measure. 0 modelo suplementar considera uma maior diversidade familiar; gastos com comida, roupas e outras necessidades básicas; considera aspectos geográfico; e a renda familiar acrescida de benefícios, mas já descontada de impostos.

3 Segundo estudos, houve uma redução no número de idosos em situação de pobreza, especialmente com a ampliação do social security e de outros auxílios sociais criados a partir de 1960.
} 
entendido como propício para a ascensão e o sucesso daqueles que se esforçavam, ou eram mais aptos ao progresso. Portanto, não caberia ao governo cuidar dos necessitados, tendo em vista que a condição social seria uma consequência do comportamento dos pobres, não da formação da sociedade.

A criação da ideia dos EUA enquanto a terra da oportunidade, do trabalho duro e do selfmade-man, entre as suas variações desde a Marcha para o Oeste até após o período de industrialização, contribuiu para o processo de "criminalização" da pobreza. Esse processopode ser pensado tanto no aspecto do encarceramento de fato, especialmente no caso de afro-americanos e latinoamericanos, com destaque entre $1960^{4}$ e 1970 (AMERICAN ACADEMY OF ARTS \& SCIENCES, 2010), mas também na exclusão dos undeserving poors dos benefícios sociais.

No contexto da Era Progressista, Steven Diner aponta que intelectuais progressistas, reformistas, políticos e jornalistas, das mais diversas áreas e posições, desafiaram concepções sociais darwnistas que circulavam. Mesmo perdendo inúmeras batalhas sociopolíticas e econômicas, defenderam um governo mais ativo (DINER, 1999,7). Naquele contexto, a democracia parecia ameaçada com a industrialização da "Era Dourada" americana. Por isso, seria importante restaurar a autonomia individual para preservá-la. Em meio ao domínio das grandes indústrias e industriais das relações socioeconômicas, o modelo capitalista americano passou a esbarrar nas desigualdades e ameaças à liberdade dos cidadãos comuns. Dessa maneira, a Era Progressista representou um período de construção de inúmeras críticas ao capitalismo (GERSTLE, 1994). Já no campo dos programas sociais, a maior parte era desenvolvido no âmbito privado (IDEM,p.1044). A ampliação do papel do Estado nesse sentido, só se desenvolveu no governo FDR e após a Crise de 1929.

A aprovação do Social Security Act (SSA), em 1935, representou um marco dentro do New Deal e das políticas de benefício social. Por atender diretamente as classes médias, o Social Security entrou na categoria dos seguros sociais, como o seguro-desemprego e o Medicare (KATZ, 1996, Posição 5336), sem supostamente gerar dependência social ou outros "riscos" para o universo do trabalho. O Social Security previa uma ação dupla de amparo social. Incluía a assistência pública para idosos, aposentados, crianças em famílias com um só responsável, crianças com deficiência e cegos, bem como verbas federais para a saúde pública local e estadual, através do pagamento de impostos. Ou seja, a princípio, beneficiaria aqueles grupos que se mantinham historicamente entre os proporcionalmente mais pobres.

Apesar de um projeto importante para o benefício dos idosos, o Social Security excluía os trabalhadores domésticos e rurais, em sua maioria afro-americanos. Dessa maneira, se integrou perfeitamente às restrições da época, em especial ao esforço de políticos do Sul em excluir ou dificultar o acesso de auxílios governamentais pelos afro-americanos. Os estados tinham autonomia para administrar o programa, garantindo assim que muitos deles fizessem uso de táticas de exclusão social. Ao mesmo tempo, os new dealers priorizavam os projetos que tivessem também algum papel para a questão da economia, e o Social Security foi visto como uma arma importante para ampliar o consumo interno. Sendo assim, o New Deal manifestava os entraves estabelecidos por políticos conservadores e racistas que marcaram as negociações no Congresso naquele período. Sem negar

\footnotetext{
${ }^{4}$ A tese defendida por Elizabeth Hinton mostra que a War on Poverty, a partir da War on Crime, facilitou o processo de encarceramento em massa da população afro-americana a partir de meados de 1960. Sobre: HINTON, E. From the War on Poverty to the War on Crime: The Making of Mass Incarceration in America. Cambridge: Harvard University Press, 2016. Entre os inúmeros trabalhos sobre o encarceramento em massa da população afro-americana: PATILLO, Mary E. et al. Imprisoning America: The Social Effects of Mass Incarceration. New York: Russell Sage Foundation, 2004; Gottschalk, Marie. The Prison and the Gallows: The Politics of Mass Incarceration in America. New York: Cambridge University Press, 2006.
} 
a sua importância, já que ampliou o espaço para reformas sociais, acelerou a melhoria nas condições de vida dos grupos de minoria e auxiliou um aumento na classe média afro-americana, cabe perceber que não houve o mesmo impacto transformador quando comparado com os resultados para a população branca.

Pensando o século XX, com destaque para as políticas públicas e legislações de promoção de benefícios entre 1930 e 1940, Ira Katznelson (KATZNELSON, 2015) defende a tese de que os Estados Unidos teriam criado uma espécie de política de ação afirmativa para brancos. Ilustrando seu argumento em números, o autor ressalta que o número de pessoas brancas vivendo em pobreza caiu 27\%, desde 1947, enquanto de pessoas "não-brancas" apenas 3\%, entre as décadas de 40 e 50 (Idem, Posição 429 - 433). Já entre 1940 e 1962, a taxa de mortalidade infantil de "não-brancos" passou de $70 \%$ maior para $90 \%$ maior do que a dos brancos. O isolamento dos afro-americanos em relação às comunidades brancas também foi ampliado (IDEM). No Norte, esse isolamento esteve conectado ao processo de migração de afro-americanos do Sul e do crescimento dos subúrbios. Houve uma ampliação dos guetos e da separação destes em relação aos bairros de classe média. Era uma diferença significativa, especialmente ao comparar com o mapa habitacional da transição dos séculos e a proximidade entre brancos pobres e de classe média. Se por um lado a distância física das moradias afro-americanas e brancas não era exatamente uma novidade ${ }^{5}$, por outro lado, o crescimento desse isolamento se refletiu em um afastamento cada vez maior na questão das relações sociais, para além das de cunho econômico e estrutural, considerando educação, saúde e infraestrutura ${ }^{6}$.

Retomando o texto de Katznelson, ele demonstra, bem como inúmeros outros estudos ${ }^{7}$, como essa segregação ampliou os custos de vida para a população afro-americana, que precisava pagar mais por gás de cozinha, aluguel e remédios do que os brancos que viviam em bairros de classe média e com melhor qualidade de vida. Os brancos normalmente eram os donos das empresas e imóveis em questão e, por isso, cobravam desproporcionalmente mais em bairros afro-americanos. Apesar das políticas do New Deal serem universalistas, os gastos do governo eram significativamente díspares. A autonomia dos estados abria margem para esse problema. Em 1940, o investimento nas escolas sulistas para alunos brancos era de $\$ 162$ e para alunos afro-americanos era de \$34 (KATNZELSON, 2005, Posição 815-818). A estrutura das escolas, os equipamentos, conforto proporcionado aos alunos, iluminação, saneamento, alimentação e bibliotecas não eram as mesmas. Ou seja, alguns governos investiam muito mais na educação e bem-estar dos brancos.

Especificamente acerca dos arranjos políticos entre as alas do Partido Democrata, que permitiram exclusões e exceções no Social Security e legislações no contexto do New Deal, Katznelson defende que:

No contexto político definido pela estranha aliança entre "companheiros de cama" do Partido Democrata, essas exclusões compreendiam o que o Cientista Político Robert Lieberman acertadamente chamou de "descriminação como projeto" através de provisões "profundamente raciais" com a capacidade e objetivo de "dividir a população em linhas raciais sem especificar". 8 (KATZNELSON, 2005, Posição 998-1004).

\footnotetext{
${ }^{5}$ Sobre o tema: Du Bois. Philadelphia Negro.; Douglas S. Massey and Nancy A. Denton, American Apartheid: Segregation and the Making of the Underclass; C. Vann Woodward, The Strange Career of Jim Crow.

${ }^{6}$ Sobre isso: Du Bois. Philadelphia Negro e Michael Harrington, The Other America.

7 Sobre isso: Du Bois, Philadelphia Negro; C. Vann Woodward, The Strange Career of Jim Crow; Herbin-Triant, Race and Class Friction in North.

8 Tradução minha. Original: In the political context defined by the strange bedfellows alliance of the Democratic Party, these exclusions comprised what the political scientist Robert Lieberman aptly has called 
Entre 1947 e 1956 a pobreza reduziu de 32\% para 23\%, uma queda de 9\% (LAMPMAN, 1965). Apesar das limitações e dificuldades encontradas pelo New Deal, a expansão da economia americana e os projetos nacionais do governo FDR abriram um espaço maior para vozes reivindicadoras de reformas sociais. Algumas dessas demandas foram incorporadas, inclusive das que circulavam entre os grupos mais progressistas da sociedade, tanto entre intelectuais como entre ativistas. As percepções da redução da pobreza, da ascensão econômica, da profunda diferença entre os Estados Unidos durante a Grande Depressão e após a Segunda Guerra, impactaram profundamente os debates intelectuais, nutrindo o otimismo liberal que se expandia.

\section{Pobreza: as variadas concepções e dimensões nos textos de intelectuais}

Publicado em 1944, o livro “An American Dilemma” de Gunnar Myrdal desenvolveu uma intensa pesquisa sobre a situação dos afro-americanos nos Estados Unidos. A iniciativa contou com o financiamento da Carnegie Corporation de Nova Iorque. Sueco, o economista iniciou seus estudos no final da década de 1930 com o objetivo de entender a questão racial americana enquanto um fenômeno social. Sua publicação se tornou uma referência no estudo do racismo e da desigualdade do país até os dias atuais. Os patrocinadores procuraram Myrdal focados no fato de que o trabalho deveria ser objetivo e isento de paixões ${ }^{9}$. Curiosamente, este teria sido o motivo pelo qual W.E.B. Du Bois não foi convidado pela corporação para dirigir a pesquisa ${ }^{10}$. Não acreditavam que um autor afro-americano seria capaz de conduzir um estudo "isento" sobre o tema, mesmo ele sendo o responsável pelo primeiro texto sociológico do país que pensava a questão racial e a desigualdade nos Estados Unidos, o "Philadelphia Negro" de 1899. Seria no mínimo contraditório uma companhia financiar uma pesquisa para compreender os problemas do racismo e suas consequências na sociedade, mas não confiar em um dos principais intelectuais e sociólogos americanos para fazê-lo, com base em preconceitos. Mais irônico é o fato de que Myrdal, um economista liberal ao modelo americano, não sofreu nenhuma desconfiança para elaborar um projeto que elegeu o liberalismo como um dos seus pilares centrais. Myrdal, afinal de contas, era branco.

O economista estruturou sua tese a partir da contradição entre uma suposta tradição liberal americana versus o racismo, a segregação e uma sociedade de castas criada, segundo ele, especificamente no Sul. Ao discutir como os afro-americanos eram tratados na sociedade, Myrdal aponta para uma separação entre Norte e Sul. Em ambos o racismo existiria, mas no Norte o preconceito seria punido (MYRDAL, 1975, p.67). Ou seja, no Norte já existia um maior esforço para combater o problema. De acordo com o autor: "Há muitos Nortistas instruídos e bem informados sobre problemas estrangeiros, mas quase que absolutamente ignorantes sobre as condições dos negros, tanto em sua própria cidade, quanto na nação (...) Muitos nortistas, talvez a maioria, ficam chocados e abalados quando descobrem tais fatos.”11 (IDEM,p.48). Enquanto o sulista também seria

"discrimination by design" by means of "race-laden" provisions with the capacity and intent "to divide the population along racial lines without saying so in so many words."

9 Myrdal usa o termo dispassionate.

10 Segundo discussão realizada no dia 28 de outubro de 2018 no Simpósio Scholarship Above the Veil: $A$ Sesquicentennial symposium honoring W.E.B Du Bois (1868 - 2018), na mesa "Race, Epistemology and the Canon" da Universidade de Harvard com patrocínio de: Harvard University's Faculty of Arts \& Sciences Division of Social Science, o Office of the Vice Provost for Research, o Weatherhead Center for International Affairs, e the Departments of Sociology and African \& African American Studies.

11 Tradução própria. Original: There are many educated Northerners who are well informed about foreign problems but almost absolutely ignorant about Negro conditions both in their own city and in the nation (...)A great many Northerners, perhaps the majority, get shocked and shaken in their conscience when they 
ignorante, em referência ao seu modo de pensar, os brancos nortistas estariam em ignorância por não conhecerem a realidade vivida pelos afro-americanos. Por isso, Myrdal acreditava que a maioria estaria plenamente disposta a ajudar os afro-americanos, caso fossem bem informados. Similarmente, ele defende que boa parte dos sulistas, caso compreendessem de fato a situação de vida e a complexidade do sistema racista americano, também apoiaria uma maior justiça para os afro-americanos (IDEM, p.48).

O liberalismo era parte fulcral do que Myrdal chamava de credo americano. Portanto, influência ideológica importantíssima para aproximar grupos de minorias, aliar ideologicamente os problemas em questão e contribuir para a construção das demandas desses grupos. (IDEM, p.73). Percebendo a educação como meio para superar o racismo, o economista defendeu que as teorias racialistas utilizadas para racionalizar o sistema de castas sulista já não eram mais aceitas pela população instruída e pelos intelectuais no contexto da Segunda Guerra (IDEM,p.1003). Alegadamente banidas de jornais e livros, as teorias estariam sendo superadas pelo avanço da informação e representariam um ponto sem retorno na disseminação dos estudos de antropologia, ciências sociais, educação e psicologia. Para ele, tal mudança teria alcançado também o governo, tendo este deixado de ser um promotor das crenças racistas.

O otimismo de Myrdal é inegável em inúmeros aspectos. A perspectiva de que o "credo americano" não comportaria o racismo foi criticado por Jennifer Hochschild (HOSCHSCHILD, 1984) e retomado por Liberman (LIERBERMAN, 1998) que relembram como a ordem política americana foi construída com base na dominação racial ${ }^{12}$. Portanto, ver o racismo como uma anomalia parece ignorar vários aspectos do desenvolvimento da sociedade e economia americanas. Os liberais brancos, identificados por ele enquanto elementos que difundiam a educação sobre o assunto, não tinham a expressão nacional que ele sugere, inclusive se pensarmos no Partido Democrata. Houve um aumento no número de intelectuais progressistas e liberais, assim como de políticos, participando e influenciando o Partido e os debates nacionais. Entretanto, seria equivocado entender essa presença como avanço sem retorno em relação as teorias racialistas e ideais que embasavam a defesa da segregação. As dificuldades de aprovação das legislações do New Deal com maior efeito reformista, a preocupação do governo em não prorrogar demasiadamente os projetos de emprego público e a necessidade de manter constantes negociações com os sulistas democratas e republicanos, barganhando o controle dos auxílios sociais e abrindo margem para exclusão dos afro-americanos, demonstram como a situação era crítica.

A força do Partido Democrata no Sul fez com que a ascensão interna dos grupos liberais e progressistas causasse uma série de conflitos, contribuindo enormemente para o processo de realinhamento ${ }^{13}$ do Partido, que já ocorria graças à mudança do eleitorado afro-americano. Ainda assim, as disputas intrapartidárias eram intensas e não havia um predomínio tão evidente de liberais democratas no momento em que Myrdal escreveu sua pesquisa. E mesmo nos governos de

learn the facts.

12 Apesar dessa discussão não ser nosso objetivo, pode-se afirmar que a ideia de liberdade na Declaração de Independência não era para todos os habitantes do recém-formado país. A manutenção da escravidão e suas consequências eram bases para o funcionamento daquela sociedade e sua economia.

13 Sobre: SELFA, Lance. The Democrats: A Critical History. Chicago: Haymarket Books, 2008. Versão Kindle.; KYDER, Daniel; KATZNELSON, Ira; GEIGER, Kim. "Limiting Liberalism: The Southern Veto in Congress 1933 - 1950". Political Science Quarterly, Vol. 108, No. 2 (Summer, 1993), pp. 283-306.; BLACK, Merle. "The Transformation of the Southern Democratic Party". The Journal of. Politics, 66 n. 4, 2004.pp.1001-1017; WARE, Alan. The Democratic Party Heads North, 1877-1962. Cambridge: Cambridge University Press, 2006. 
Kennedy e Johnson, o Partido como um todo não era homogeneamente liberal. O contexto observado por Myrdal é aquele que identificamos como um período de grande privilégio das classes médias, principalmente brancas, através de patrocínio governamental. O otimismo de Myrdal impactou igualmente a percepção da pobreza naquele momento entre intelectuais. Sua teoria de que existia um imutável progresso no país, de superação da segregação e do racismo, em associação com sua ideia de que a situação econômica dos afro-americanos era parte de um ciclo, contribuiu para uma falsa noção de "evolução" daquela sociedade, cada vez menos preconceituosa e mais "instruída". Lembrando que, para Myrdal, "instrução" era sinônimo de uma posição antirracista e liberal. Assim, alimentava a perspectiva de que o fim do racismo seria apenas uma questão de tempo.

Myrdal conectava a pobreza com uma interdependência daquilo que chamava de "negro problem" (MYRDAL, 1975, p.75). Assim, o preconceito e discriminação propagada pelos brancos manteriam os afro-americanos em baixos padrões de vida, saúde, educação, maneiras e moral, o que, por sua vez, alimentaria os preconceitos dos brancos. Nesse sentido, ele afirma que "o preconceito branco e os padrões negros "causam" mutuamente um ao outro" (IDEM) ${ }^{14}$ Por isso, destaca-se a confiança do economista na presumida progressão da educação da sociedade americana, disseminada por liberais brancos e o tal "credo americano". O ciclo de pobreza abordado por Myrdal foi trabalho de forma similar por autores liberais e progressistas entre 1950 e 1960 . O otimismo em relação à superação do racismo foi levado para o tema da pobreza. Especialmente no contexto do pós-guerra, a expansão da economia mascarava a manutenção do pauperismo no país.

No Norte, o racismo foi visto enquanto algo sulista, reflexo de uma menor "evolução" da região. Enquanto isso, a inferioridade dos ditos "padrões" afro-americanos, em aspecto moral e cultural, foram profundamente estudados na década de 1960 e associados à tal cultura da pobreza. O problema passou a ser frequentemente justificado por meios comportamentais, o que reduzia o impacto do racismo e da desigualdade nessas análises. Já a menor percepção da pobreza esteve relacionada à menor visibilidade, tanto pela expansão dos subúrbios e maior exclusão dos guetos, como pela efetiva redução do problema. Similarmente ao modo com que Myrdal encarou a "evolução" da sociedade quanto ao racismo, a ascensão econômica americana foi absorvida como um ponto quase sem retorno. E se a pobreza e o racismo tinham dimensões exclusivamente cíclicas, o tempo seria efetivo na eliminação de ambos.

Lançado em 1899, o livro "The Philadelphia Negro: A Social Study” de W.E.B Du Bois trouxe uma pesquisa encomendado pela Universidade da Pensilvânia. O primeiro estudo de caso sobre uma comunidade afro-americana publicado nos Estados Unidos, o livro se dedicou ao debate da pobreza no país e discutiu inúmeros dos temas que outros estudiosos se debruçaram entre 1950 e 1960, apesar de sem fazerem referências à Du Bois. Primeiro trabalho científico sobre raça sem utilizar uma tradição racista, e um dos primeiros trabalhos das ciências sociais que se baseou em estatísticas para pensar a pobreza afro-americana (ANDERSON, "Introduction" in DU BOIS, 1996), Philadelphia Negro é uma reflexão inicial de Du Bois e demonstra um processo inicial de construção do pensamento $d u$ bosialiano.

Em Philadelphia Negro, Du Bois desenvolve um estudo de caso sobre a comunidade afroamericana da região, especialmente a área da Seventh Ward. A sua construção analítica sobre a vida dessa população, englobava a relação de aspectos macro e micro como escravidão, emancipação, segregação, educação, ocupação, habitação, saúde, vida em comunidade e problemas sociais na

14 Tradução propria. Original: "White prejudice and Negro standards thus mutually "cause" each other". 
Filadélfia. Du Bois também se preocupava em desmistificar abordagens que particularizavam a violência como algo intrínseco ao grupo. Defendendo a compreensão do crescimento no número de presos afro-americanos em um contexto de problemas sociais e não biológicos, associou as altas taxas de criminalidade com a questão da migração urbana. O sociólogo destacou como a migração branca entre 1820 e 1830 foi marcada por um aumento na criminalidade. Por outro lado, as prisões dos afro-americanos teriam um alto número por estarem repletas de prisões arbitrárias, sem justificativas, com acusações e condenações sem provas (DU BOIS, 1996, p.246). A violência policial e arbitrariedade nas prisões se manteve como um tema fulcral ao longo do século XX, sendo fundamental para a criação do Partido dos Panteras Negras posteriormente. Sendo assim, a situação denunciada por Du Bois entre 1836 e 1855, permaneceu, e ainda permanece afetando a vida dos afro-americanos.

A criminalidade deveria ser entendida a partir das condições sociais e das consequências do racismo vigente. Ao contrário do senso comum, a posição de "classe baixa" do afro-americano deveria ser um dos principais fatores a serem considerados para entender não só a questão da violência, mas também da pobreza (IDEM, p.274). De acordo com o autor, "como a condição de uma classe baixa é por sua definição muito pior do que a da classe alta, então a situação dos negros é pior, no que diz respeito ao crime e à pobreza, do que a da massa de brancos." (IDEM, p. 282283). O status de classe baixa, auferido desde o processo de emancipação, potencializaria os indicadores sociais negativos. Se houvesse uma crise econômica, os afro-americanos sofreriam mais, se houvesse um aumento nos números da violência, ele seria maior entre eles, se houvesse uma piora na condição da pobreza, ela também seria mais agravante. (IDEM). Os dados sobre a pobreza levantados entre 1950 e 1960, corroboram com a tese de Du Bois. Nesse sentido, a busca por melhores condições de vida, emprego, educação e habitação no cenário do novo ambiente industrial do século XIX, era mais desafiador para a população afro-americana.

O autor destacou os processos de escravidão e emancipação, migração urbana e o ambiente social onde o grupo era imerso. Em seus estudos, percebeu consequências negativas como o desencorajamento, reprodução de ideias de inferioridade, ausência de reconhecimento enquanto membros daquela sociedade, gerando uma maior ignorância e pouca disciplina (IDEM). Similarmente à ideia de ciclo de pobreza, Du Bois pensava as consequências materiais e psicológicas que afetavam o comportamento, o pensamento, a atitude dos afro-americanos e contribuíam para a manutenção das suas condições de vida. No entanto, Du Bois colocava essas consequências em segundo plano, destacando a ação da construção racializada das relações entre brancos e afro-americanos, da negação da identidade e humanidade dos últimos e exclusão social, econômica e cultural daquela sociedade. Ao decorrer de sua análise sobre as condições de vida na Seventh $W$ ard, Du Bois procura entender a influência das habitações e da atmosfera social na vida destes, considerando os impactos psicológicos e de desenvolvimento pessoal ou familiar, direcionando essas populações para uma vida atrelada ao desperdício e crime. Há um aspecto moralizante em algumas das observações de Du Bois, condenando a participação em jogos e idas aos saloons, o que não era restrito aos mais pobres ou minorias raciais.

O capítulo "The contact of the races" é o mais relevante para pensar o impacto do racismo nas relações sociais e algumas outras considerações, já no sentido da teoria de Consciência Dupla ${ }^{15}$.

${ }^{15}$ A ideia de Consciência Dupla, cunhada entre as obras Souls of Black Folks e Dusk of Dawn, abordaria a autoformarão afro-americana em uma sociedade racializada. Para Du Bois, o afro-americano não tinha espaço para o desenvolvimento de uma consciência própria, olhando para si através do olhar do branco, entendendo-se a partir dos padrões desse mundo que o inferiorizava. Sua identidade estaria multifacetada. 
Nele, há o debate da ausência de percepção dos brancos das suas ações e suas consequências. Enquanto os afro-americanos apontavam para o racismo como fator determinante para suas condições de vida, os brancos viam "apenas" suas escolhas de não se relacionar com uma raça supostamente inferior dentro dos padrões culturais da época, não entendiam como suas ações e esse sentimento de inferiorização afetavam e influenciavam as condições sociais dos primeiros. Como demonstra Du Bois, a partir dessa visão hierárquica dos brancos, existia menor oportunidade no mercado de trabalho, as minorias raciais recebiam menores salários e tinham uma condição de mobilidade social mais reduzida. Os serviços destinados também eram piores, os aluguéis eram proporcionalmente mais caros, as crianças cresciam em piores condições de vida e a etiqueta social exigida em várias regiões era degradante. As expectativas dos jovens eram extremamente diferentes. Até mesmo o jovem afro-americano que conseguisse se formar em uma universidade, dificilmente conseguiria um emprego em sua área de formação ou com salários similares aos brancos. Relatos do final do século XIX, essas mesmas condições eram denunciadas em meados do século XX.

Para justificar a falta de oportunidade para jovens afro-americanos, Du Bois recolheu inúmeros depoimentos que defendiam uma menor habilidade e talento por parte deles, se comparado aos jovens brancos. Nesse sentido, Du Bois denunciou o preconceito racial enraizado que impedia jovens qualificados a atuarem em suas áreas de formação. A mobilidade social e rompimento com as condições de pobreza e limitação social não seriam superadas apenas com a qualificação. $O$ racismo se mantinha como principal barreira institucional. Entre os trabalhadores, a exclusão sindical e associação com trabalhos domésticos, "por excelência", eram fatores limitadores dentro do mercado de trabalho. Ademais, o salário mínimo, e outros benefícios destinados aos trabalhadores, excluíram os trabalhadores rurais, domésticos e várias outras funções sem apoio sindical durante o século XX. A própria classe trabalhadora e pobre branca evitava ter contato ou se misturar com os afro-americanos naquele contexto estudado por Du Bois. Assim, estes tinham os piores contratos de trabalho; pagavam mais pelo aluguel em bairros segregados, com pior infraestrutura, pois os imóveis pertenciam geralmente aos brancos que não reparavam as casas e tinham condições insalubres e viviam em bairros cada vez mais desvalorizados e abandonados. Essa realidade se manteve e se ampliou nos guetos urbanos ao longo do tempo.

A conexão entre o preconceito, o crime e a pobreza não era algo simplificado. Como disse Du Bois, o jovem que não era promovido no trabalho por causa da sua cor não iria imediatamente se tornar um ladrão. Era necessário entender a complexidade da revolta, indignação, a falta de reconhecimento enquanto indivíduo capaz, o ambiente social de desespero, descuidado, a ausência de incentivos e motivação que paulatinamente foi construído. Sem oportunidades e sem chances de progredir, mesmo quando educados e qualificados, os afro-americanos sofriam o desprezo e as consequências de um processo de inferiorização social, responsável por mantê-los enquanto uma lower class. Nas palavras de Du Bois: "por quanto tempo uma cidade irá ensinar aos seus jovens negros de que o caminho para o sucesso é ter um rosto branco?" ${ }^{16}$ (Idem, p.351) Até onde o esforço pessoal poderia superar as barreiras impostas pelo racismo? Se torna cada vez mais evidente como a pobreza afro-americana é absolutamente particular na história dos Estados Unidos. Era uma sociedade hierarquizada racialmente, e estes estavam na base dessa pirâmide, desprezados e tratados como indignos de trabalho, educação e cidadania. Em uma leitura das propostas de Du

Ser americano e negro era o desafio naquele universo que o excluía e não o reconhecia.

16 Tradução minha. Original: "how long can a city teach its black children that the road to success is to have a white face?" 
Bois, atacar apenas um dos problemas vividos pelo grupo não seria suficiente para superá-los. Era necessário entender a combinação dos fatores formando um problema social e não só um problema individual.

Em contraste com a construção Myrdaliana de um suposto credo americano liberal e inclusivo, em que o racismo seria uma contradição, Du Bois explorou como a estrutura daquela sociedade era amplamente conectada à questão racial, não sendo possível separar ou entender os Estados Unidos sem essa particularidade. Para entender o problema da pobreza no país, a partícula racial também não poderia ser descolada. No entanto, ao modo oposto proposto por Du Bois, boa parte dos intelectuais responsáveis por pensar políticas públicas na década de 1960 colocou a pobreza, a ignorância e a degradação social enquanto causa principal para refletir sobre o tema e buscar soluções, e não consequências. Ainda que falando sobre boa parte dos elementos discutidos pelos intelectuais brancos de 1950 e 1960, Du Bois não foi recuperado em seus trabalhos. Myrdal dialogou com Du Bois em seu texto, mas quando precisava citar o trabalho de algum intelectual afro-americano. A exclusão racial apontada por Du Bois enquanto um fenômeno social se manifestava também no campo do debate intelectual.

Entre os trabalhos que reproduziam o otimismo em relação ao crescimento da economia americana, o economista John Kenneth Galbraith publicou o livro "The Affluent Society” em 1958. Financiado pela Guggenheim Foundation, o projeto inicial deveria ser o desenvolvimento de um estudo sobre a pobreza. No entanto, segundo o autor, ele estudou a afluência. Indo mais além, observa-se que o livro se dedica a compreender o investimento de gastos públicos versus os gastos privados, bem como o seu reflexo e significado, em um contexto de enriquecimento econômico nos Estados Unidos. Para ele, a pobreza estava cada vez mais restrita e localizada, dificultando o seu combate e a sua visibilidade. Sem negar a permanência da pobreza, Galbraith a identifica enquanto uma "reflexão de segundo plano" para sociedade americana de 1950, o que lhe rendeu suas principais críticas. Ele divide em dois os grupos que ainda viviam em pobreza naquele momento. A case poverty "seria comumente e apropriadamente relacionada à algumas características dos indivíduos por ela afligidos" (GALBRAITH, p.205) ${ }^{17}$. Atingiria aqueles com problemas individuais propiciadoras da pobreza como: deficiência, vícios, ignorância, restrições e exclusão social. Já a insular poverty, seria aquela de determinadas regiões isoladas e perpetuada ciclicamente pela pobreza e falta de oportunidade lá presentes (IDEM). Dessa maneira, a primeira teria um aspecto mais individualizante e a última, conectada com o ambiente onde as pessoas viviam.

Observando sua divisão em duas formas de gerar a pobreza, uma individualizante e outra determinada pelo ambiente, percebe-se que Galbraith traz elementos culpabilizantes dos indivíduos. Além disso, o problema aparece em seu texto como uma doença na sociedade, mas uma doença que se tornava cada vez menos aparente. De alguma maneira, essa ênfase na especificidade do tema refletia um otimismo do "progresso" americano e alimentou uma visão de país supostamente afluente, a pobreza seria uma exceção. De forma parecida com Myrdal, Galbraith transpareceu uma crença no "desenvolvimento" do país. Em contrapartida, manifestou preocupações com a manutenção desse "resquício" de pauperismo. O investimento nos jovens e crianças foi uma das soluções levantadas e defendidas pelo autor ao longo de sua obra. "A pobreza é auto-perpetuante, em parte porque as comunidades mais pobres são mais pobres nos serviços que a eliminariam. Para eliminá-la com eficiência, nós deve, de fato, investir mais do que proporcionalmente nos filhos das

17 Tradução minha. Original: Case poverty is commonly and properly related to some characteristic of the individuals so afflicted. 
comunidades pobres". (IDEM, p.209)

Como demonstrado por Galbraith, a visão da pobreza enquanto autoperpetuada era bastante comum entre 1950 e 1960. Por isso, o investimento em regiões desfavorecidas e uma melhor educação, treinamento e saúde para as populações marginalizadas, seriam algumas das chaves para resolver o problema da manutenção da pobreza. Contudo, o autor pouco escreve sobre os motivos que causaram uma discrepância tão grande entre essas regiões e as demais, entendidas como de sucesso. Ainda que não fosse o foco do trabalho, como Galbraith enfatiza aspectos individualizantes e cíclicos da pobreza enquanto elementos perpetuadores, caberia uma crítica mais profunda acerca das desigualdades existentes no país, principalmente porque o autor cobra desses grupos marginalizados uma integração ao modelo de "sucesso" americano. Aqueles que não se adequassem, seja por "virtude pessoal" ou ambiente, não teriam como "progredir".

Outra questão importante é o modo como ele propõem uma reforma urbana americana. Por todos os problemas envolvendo a segregação, a migração afro-americana, a criação dos subúrbios e o isolamento dos guetos, uma reforma urbana era algo interessante no sentido de reduzir as discrepâncias regionais. Porém, Galbraith fala em uma "frustração" dos últimos com os primeiros para entender essa relação, o que não necessariamente a caracterizaria. Ele defende uma reorganização no campo e nas cidades, financiada pelo Estado, mas ao enfatizar um sentimento de "frustração" por parte dos mais pobres, retira um pouco do impacto fundamental das questões econômicas e sociais envolvidas no processo de exclusão das populações dos guetos. A frustração não era necessariamente com os subúrbios, estes seriam uma concretização física do processo que ampliou essa exclusão urbana. Ademais, ao propor que o governo, por ser afluente, financie projetos chamados por ele de "qualitativos" para redução da pobreza, Galbraith demonstra seu otimismo no processo de enriquecimento do país, da presença limitada desta e pensa muito pouco nos limites sociais da sua ideia, ou seja, na questão do apoio popular. Será que essa mesma população que naturalizava a desigualdade, de caráter consideravelmente racial, apoiaria um amplo projeto modificador dessas estruturas habitacionais para reduzir o isolamento dos moradores dos guetos?

A tese de Galbraith foi profundamente $\operatorname{criticada}^{18}$ por estudar mais a afluência do que a pobreza e reduzir tanto a sua dimensão como os motivos pelos quais ela existia. De fato, a compreensão de Galbraith era circunscrita a alguns casos específicos. Restritas à case poverty e insular poverty, a construção da pobreza era, ou consequência de problemas individuais, ou cíclica, sendo ambos, como ressalta Anderson, entendimentos estruturais da questão. Por esse motivo, não necessariamente seria resolvido com a manutenção da ascensão econômica do país (ANDERSON, 1967 ,p.73). Em "Affluent Society", o autor frisa a importância dos tais investimentos sociais para liquidar o pauperismo remanescente, justamente por não entender o desenvolvimento da economia e da indústria enquanto agentes capazes de eliminá-lo. Naquele contexto, o problema tinha suas especificidades. O papel dessa riqueza era proporcionar os meios de patrocínio. Outro fator delimitador da percepção da pobreza em seu texto é a ênfase em como esta não seria mais a de 1930 ou a mesma de países chamados de subdesenvolvidos. Era o tempo de uma "nova pobreza", de uma sociedade que possuía alimento, roupas e habitações e passou a demandar outras necessidades como ruas limpas, policiamento, controle de epidemias, etc (GALBRAITH, p.10). A compreensão de Galbraith reflete o chamado "otimismo liberal” na visão do país e demonstra o quão invisível a

\footnotetext{
18 Ao exemplos de: HARRINGTON, Michael. The Other America: Poverty in the United States. New York: Macmillan, 1962; TRATTNER, Walter I. From Poor Law to Welfare State: A History of Social Welfare in America. Nova York: The Free Press, 1999. PATTERSON, James. America's Struggle Against Poverty in the Twentieth Century. Massachussetts: Harvard University Press, 2000.
} 
questão era para alguns desses intelectuais liberais. Sabe-se que o entendimento de pobre se modifica, mas isso não significava a ausência de questões como a fome ou a falta de habitações dignas. Essa última, inclusive, relacionada à guetificação das regiões urbanas.

Retomando as críticas à Galbraith, cobrar do autor uma análise mais profunda da pobreza e da desigualdade parece exigir algo além da sua proposta. O livro não era um estudo sobre o tema. Apesar de ter um papel importante em sua tese, o economista debate temas como a história dos pensamentos econômicos, desconfiança econômica sobre o governo, a inflação, balança social, investimentos públicos e privados, serviços públicos e privados e a produção versus consumo, para pensar como a produção de bens e serviços era primordial na busca pelo êxito social. Dessa maneira, seu foco era um debate econômico e o desenvolvimento de propostas para utilizar a suposta afluência daquela sociedade para melhorá-la. Entende-se que o grande problema é a dimensão atribuída por ela para a pobreza, bem como a sua conceitualização desta, e não o seu foco estar em outras questões econômicas. Ademais, seus pontos de vista quanto a pobreza influenciaram a Guerra à Pobreza em conjunto com outros autores da época que a pensavam de forma cíclica, individualizante e defendiam a necessidade da sociedade "civilizada" (IDEM, p.IX) ${ }^{19}$ intervir e guiar as populações pobres na superação de características ou "doenças sociais" responsáveis por mantê-los naquela situação. Mesmo sua abordagem não sendo pautada em questões culturais, alguns dos seus argumentos foram cruzados com essa vertente de compreensão da pobreza durante o governo Johnson.

O antropólogo Oscar Lewis se tornou a principal referência de abordagens culturais acerca da pobreza nesse contexto. Publicado em 1959, "Five Families: Mexican Case Studies in the Culture of Poverty” foi, segundo Margaret Mead, o primeiro trabalho da área disposto a entender a cultura da pobreza através de uma análise etnográfica. O livro foi desenvolvido a partir de um estudo de caso com cinco famílias mexicanas. O objetivo de Lewis era explorar as nuances da pobreza mexicana e mundial, já que o estudioso via de forma global certas características das famílias desfavorecidas. Enfatizando fatores psicológicos, o que pensavam e o que sentiam, desejava reconsiderar a atuação do seu campo de estudo, alargando-a para questões que afetavam mais diretamente a sociedade americana e as relações internacionais ${ }^{20}$. Aos antropólogos, caberia o dever de estudar as populações pobres considerando a pobreza moderna e não a presente nas civilizações isoladas que muitos estudavam. Para ele, a questão teria se tornado um fator dinâmico capaz de afetar a participação na cultura nacional, assim como de criar uma subcultura própria que, por sua vez, criaria consequências psicológicas e sociais especificas aos seus “membros” (LEWIS, 1959, pp.1-2).

$\mathrm{Na}$ concepção da Lewis, a cultura da pobreza era independente do local onde as populações pobres viviam, podendo ser similar no campo e na cidade ou até mesmo entre nações distintas. Por isso, a cultura da pobreza não seria contida por barreiras nacionais, associada ao modo de vida das pessoas e não da sua origem (Idem, Ibidem, p.3). Naquele período, Lewis inspirou a ampliação da ênfase no impacto psicológico do problema nos debates intelectuais. Naquele contexto, alguns críticos, especialmente membros de movimentos sociais afro-americanos, como Martin Luther King e Bayard Rustin, alertavam para como essa "preocupação" psicológica e cultural retirava a ênfase de questões sociais e econômicas impactantes para entender a desigualdade e o pauperismo nos Estados Unidos. Contemporaneamente, outros autores ${ }^{21}$ corroboraram essa tese. Para esses

19 Galbraith usa o termo "sucesso civilizado" para pensar o êxito do projeto de êxito social.

20 Lewis estava bastante preocupado com as influências materialistas americanas na sociedade mexicana.

21 Herbin-Triant, Threatening Property:Race, Class, and Campaigns to Legislate Jim Crow Neighborhoods; Cherryl Harris, Whiteness as Property; Lee Rainwater, The Moynihan Report and the Politics of Controversy; 
críticos, psicologizar e enfatizar aspectos culturais da pobreza enquanto meio principal de entendêla, colocava em segundo plano discussões mais complexas que poderiam incluir também o impacto psicológico da exclusão e segregação, mas não somente.

O intuito de Lewis era a inovação no campo da antropologia e a revelação de novos aspectos psicodinâmicos a serem comparados com o da cultura "externa" ao pensar a cultura da pobreza a partir do estudo intensivo de eventos e problemas especiais. Ao propor pensar o tema a partir de uma cultura psicológica própria, abriu margem para interpretações individualizantes e enfaticamente culturais do problema. Se a questão era comportamental e no âmbito dos valores, os pobres precisavam ser reformados e não se beneficiarem de reformas. A cultura da pobreza foi absorvida nas políticas públicas de 1960 em um viés não tão profundo e, ainda assim, argumentou pela mudança comportamental dos mais pobres. $\mathrm{Na}$ verdade, mesmo intelectuais entendidos como progressistas, como Michael Harrington, utilizavam alguns elementos da cultura da pobreza, ainda que não da exata mesma maneira, para pensar a questão naquele momento. O conceito foi utilizado de formas distintas até sua incorporação por intelectuais conservadores após 1970. Até então, liberais e progressistas mobilizavam a ideia em seus textos e discursos.

No começo de 1960 algumas publicações questionaram a análise otimista e restritiva da pobreza das décadas anteriores. Publicado em 1962, o livro "The Other America - Poverty in the United States" de Michael Harrington se tornou um best seller no começo da década. Harrington era um socialista democrata, ativista político, autor e membro da LID - League for Industrial Democracy ${ }^{22}$. Considerado por especialistas no tema enquanto uma das principais referências na área, apesar do pouco rigor acadêmico de seu trabalho, especialmente em suas notas de referência e fontes, Harrington foi uma das primeiras vozes denunciantes do problema a serem de fato ouvidas no período. Em meio ao cenário de euforia com a situação econômica americana no pós-guerra, Harrington despontou na qualidade de crítico à pobreza após ter seu livro resenhado por Dwight Macdonald e publicado no New Yorker. Há quase uma lenda envolvendo a notoriedade que o trabalho de Harrington obteve, mas sabe-se que o artigo de Macdonald sobre Harrington foi lido pela equipe de John F. Kennedy e teria inspirado um projeto embrionário de combate à pobreza, como exploraremos na tese. Não existe comprovação de Kennedy ter lido de fato o livro de Harrington, no entanto, a publicidade gerada pelo artigo de Macdonald e pela Guerra à Pobreza de LBJ alavancaram as suas vendas.

O livro é extremamente complexo e apresenta uma quantidade bastante grande de dados e propostas sobre a pobreza. Portanto, destacaremos as teses centrais do autor e as discussões mais relevantes para o desenvolvimento desse trabalho. Um dos pontos iniciais debatidos por Harrington foi a tese de Galbraith, "Affluent Society". Entendendo o título como mal interpretado por quem ele chama de "família americana", aponta para os perigos dessa interpretação desviada no sentido de tornar a pobreza cada vez mais invisível (HARRINGTON, 1962, Posição 401), a grande questão do seu trabalho. Indo ao encontro dos argumentos de Galbraith, Harrington concorda que a pobreza não é a da miséria dos países extremamente pobres. No entanto, salienta a permanência da fome, necessidades básicas, baixa qualidade da educação e saúde de maneira mais ampla se compararmos com o primeiro. Apesar de corroborar com Galbraith entendendo a pobreza de 1950 como uma condição diferente, ainda mais se checarmos as terríveis realidades sociais existentes no

Charles Valentine, Culture and Poverty Critique and Counter.

22 Sobre a LID e outras organizações estudantis do período: FARIAS, Rodrigo. A Nova Esquerda americana: De Port Huron aos Weathermen (1960-1969). Rio de Janeiro: FGV, 2009. 
mundo, Harrington a vê de forma muito mais abrangente e profunda no país. Para ele, a fome aparecia de novas maneiras como, por exemplo, no sobrepeso entre os mais pobres, que só podiam adquirir alimentos incapazes de nutrir verdadeiramente e outros produtos de baixíssima qualidade, afetando a sua saúde tanto física quanto mental (Idem, posição 568).

Discordando quanto a visão individualizante de Galbraith na casual poverty, prefere assumir as doenças enquanto consequências da pobreza e não algo inato aos necessitados. Já para a insular poverty, alerta para o perigo de descrevê-la enquanto algo isolado, em poucos casos, comuns em locais remotos como Apalaches e Virgínia (Idem, Ibidem). De acordo com os dados de Harrington, o problema atingiria 40 milhões de pessoas e estaria longe do aspecto diminuto do livro de Galbraith. Nesse sentido, acredita-se que a principal proposta do texto de Harrington é ser um trabalho sobre pobreza para quem não era pobre, ou seja, torná-la visível após ser esquecida por boa parte da população e intelectuais. Ainda com as discordâncias, o autor salienta positivamente o papel de Galbraith em apontar a existência de uma subcultura da pobreza, ainda que não apresentada de forma forte o suficiente pelo autor para desafiar o imaginário nacional de afluência.

Uma visão cultural da pobreza, não exatamente a de Galbraith ou Lewis, também foi utilizada por Harrington, evidenciando a importância dessa perspectiva no período. Atrelado ao debate sobre a questão, o conceito de underclass - subclasse, foi questionado a partir de $1970^{23}$ por seus efeitos conservadores na compreensão da pobreza em geral e, em destaque, do pauperismo entre as minorias raciais. Por isso, o uso de tais conceitos foi se tornando quase exclusivo aos autores conservadores entre 1970 e 1980. Em "The Underclass Debate”, Michael Katz localiza no contexto das migrações afro-americanas do século XX a transformação da questão da underclass como algo concentrado aos mesmos. Aliado aos debates sobre pobreza e diferenças culturais, a discussão ganhou aspectos raciais, paulatinamente estigmatizando os afro-americanos habitantes dos centros urbanos.

O isolamento é debatido por Harrington e por outros pensadores tanto naquela época como contemporaneamente, com a retomada de estudos sobre a ideia de subclasse. $\mathrm{Na}$ ótica de Harrington, os pobres continuavam morando nas regiões centrais do país, como nos anos anteriores. A grande diferença era a saída das classes médias e trabalhadoras brancas ${ }^{24}$ dessas regiões, reduzindo drasticamente o contato da base da pirâmide econômica com outras camadas (IDEM, posição 445-446). O peso desse isolamento estaria nos âmbitos econômicos, sociais e culturais. Dentro dos debates acerca do impacto psicológico e cultural da pobreza, o isolamento era um dos fatores de destaque, sendo importante recriar o contato para os mais pobres "absorverem" um modelo de comportamento e de vida entendido como da classe média. Ao mesmo tempo, o isolamento era denunciado por Martin Luther King como um meio de excluir os mais pobres de uma infraestrutura e oportunidades existentes fora dos guetos. Sobre o impacto do isolamento social e o uso de termos como subclasse e patologia social para pensar os problemas dos guetos urbanos, William J. Wilson lançou, em 1987, o livro "The truly disadvantaged: the inner city, the underclass, and public policy”. Reconhecidamente um dos textos contemporâneos mais importantes para os estudos da história urbana ${ }^{25}$, a tese de Wilson procurava retomar debates sobre subclasse e patologias sociais, mas pensando o contexto entre 70 e 80 .

\footnotetext{
${ }^{23}$ Entre eles: Lee Rainwater, The Moynihan Report and the Politics of Controversy,

${ }^{24}$ Até mais da metade do século XX a classe média afro-americana também vivia nos guetos.

${ }^{25}$ Mesmo com críticas ao trabalho e sua tese, inúmeros autores reconhecem o papel de "Truly Disadvantaged" para retomar os estudos sobre os problemas sociais dos guetos urbanos entre estudiosos entendidos como progressistas. Alguns dos autores: Michael Katz, Paul Peterson e C. Emory Burton.
} 
Crítico da posição dos autores liberais em se afastarem do debate da subclasse pela carga conservadora adquirida, Wilson advoga os estudos nesse sentido como fundamentais para pensar os problemas sociais urbanos e o impacto do isolamento social e geográfico para os guetos (WILSON, 1987, p.7). Vale salientar que ele não defendia uma ideia de cultura da pobreza, mas sim de isolamento social para entender a associação entre a subcultura do gueto e as restrições de oportunidade. Apesar das inúmeras críticas aos seus argumentos ${ }^{26}$ e reconsideração por parte do próprio Wilson no uso de tais termos, o autor impulsionou uma renovação nos estudos da chamada subclasse americana. Concordando com Katz, defende-se que o uso contemporâneo da ideia de subclasse deve ser realizado enquanto um objeto de análise e sujeito histórico, uma metáfora de transformação social, para entender a emergência de novos grupos nas inner citys americanas. A underclass significaria um meio de entender a pobreza urbana e não uma definição das condições de vida dessa população, ou das condições que as mantém nessa situação. Por isso, quando usado o termo ao longo da tese, terá sempre o sentido histórico utilizado pelos autores destacados e estudados.

Nesse sentido, a subclasse seria formada também pelo crescente isolamento dos guetos o que, segundo Harrington, contribuiu para a invisibilidade da pobreza. Fora dos circuitos de circulação, de turismo e do contato com outras camadas sociais, "os pobres estão cada vez mais escapando da própria experiência e consciência da nação.” (HARRINGTON, 1962, Posição 446). ${ }^{27}$ Mais uma maneira de isolamento percebida por Harrington eram as políticas e leis criadas pelo New Deal, o Wagner Act e o Social Security. Sem desmerecer a relevância para combater o pauperismo, destacou a seletividade ao conceder benefícios, especialmente para trabalhadores sindicalizados brancos e a classe média, em uma maneira bastante similar a argumentada por Katznelson. Harrington procurava evidenciar como os projetos de auxílio e benefício para os mais pobres absorveram o estigma conferido aos undeserving poors e como esse estigma tinha aspectos raciais. A pobreza associada aos imigrantes europeus e ao impacto da Grande Depressão era diferente da que ele chama de "nova pobreza" de 1950 e 1960. Além de não terem sido contemplados com os benefícios de 1930 e 1940, Harrington atribui grande importância na suposta diferença de senso coletivo e psicológico dos dois grupos. Os primeiros, tinham uma maior esperança e otimismo por viverem em um ambiente igualmente otimistas, com grande mistura de pessoas e influências positivas para buscar o sucesso. Já os novos pobres viviam em exclusão e teriam menos motivação por estarem rodeados pela ideia de falha, inferioridade e não possuírem incentivos para buscar uma vida melhor, seus horizontes de expectativa eram restritos. (IDEM, Posição 552)

Esse é o tipo de afirmativa que ilustra profundamente como o trabalho de Harrington, mesmo preocupado em denunciar a manutenção da pobreza e as desigualdades existentes nos Estados Unidos, perpetuava algumas concepções individualizantes do conceito, especialmente quando tratando de aspectos culturais e psicológicos. Além disso, questionamos o quão novo o problema era, se pensarmos a extensão e dimensão dos efeitos de jim crow e a segregação. Este assume particularidades do contexto do pós-guerra, ampliação dos subúrbios, enriquecimento dos Estados Unidos e transformações do mapa habitacional, mas tem similaridades indiscutíveis com a realidade estudada por Du Bois em Philadelphia Negro, datado de 1899. A segregação é um dos

26 Wilson foi criticado por sua tese central de que a guetificação entre afro-americanos teria ampliado a partir de 1970, considerando tal fenômeno um reflexo das mudanças no mercado internacional e na economia. Wilson também foi criticado por reduzir o impacto do racismo na equação da desigualdade entre brancos e afro-americanos. Também foi criticado por defender o uso dos termos subclasse e patologias sociais para falar dos guetos afro-americanos.

27 Tradução minha. Original: The poor are increasingly slipping out of the very experience and consciousness of the nation. 
principais fatores de continuidade e parece ser negligenciada por alguns autores, incluindo Harrington, na consideração dos verdadeiros custos gerados aos afro-americanos.

Harrington desenvolveu o conceito de ciclo vicioso e o de cultura da pobreza para pensar o problema ao longo de seu trabalho. Para ele, o primeiro conceito estaria associado ao desenvolvimento de uma pobreza para além do controle daqueles acometidos por ela. Usando o termo "vítima", o autor afirma que a maioria desses pobres permanece na mesma situação de vida graças ao ciclo vicioso da pobreza em diferentes formas. Como exemplo ele cita a questão da saúde:

Os pobres adoecem mais do que qualquer outra pessoa na sociedade. Isso é porque eles vivem em favelas, amontoados em condições anti-higiênicas; eles têm dietas inadequadas e não podem arcar com cuidados médicos decentes. Quando ficam doentes, ficam doentes por mais tempo do que qualquer outro grupo da sociedade. Por estarem doentes com mais frequência e mais tempo do que qualquer outra pessoa, eles perdem pagamentos e emprego e se torna difícil manter um emprego estável. E por causa disso, eles não podem pagar por boas moradias, por uma dieta nutritiva, por médicos. ${ }^{28}$ (HARRINGTON, Posição 629)

Na sua visão, o ciclo de pobreza significaria a manutenção do aprisionamento das pessoas pobres às amarras diárias de suas vidas, responsáveis por restringirem ou impedirem o seu escape da condição de pobreza por contra própria. Essa teoria se manifesta ao longo do livro, já que Harrington constantemente advoga por uma ampliação do espaço de influência política desses grupos, para garantir a sua articulação e maior possibilidade de reivindicação social. Por outro lado, corrobora para uma posição de vítima passiva muitas vezes apresentada por ele. Sendo assim, os pobres precisariam de uma intervenção externa, de um "resgate", para se mobilizarem e transformarem as suas vidas.

A noção de uma cultura pobre inferior também afetava essa situação; se os pobres não tinham o melhor desenvolvimento cultural e psicológico por sua condição, deveriam aprender como protestar, se organizar e se mobilizar. Ainda assim, a conceituação de ciclo da pobreza foi importante para quebrar uma vertente individualizante do tema e o preconceito social que atribuiu o pauperismo ao próprio pobre. Ademais, exaltava a necessidade de ação governamental para interromper os mecanismos desse tal ciclo, posto que os indivíduos não seriam capazes de rompê-lo sozinhos. A cultura da pobreza, para Harrington, seria uma maneira mais profunda de explicar o ciclo da pobreza. (IDEM, Posição 629) Apesar do autor muitas vezes usar os termos de maneiras similares ou quase como sinônimos, a primeira seria uma reunião dos elementos cíclicos, da linguagem, da psicologia e do modo de ver o mundo das pessoas pobres.

Todavia, acredita-se que a ideia de ciclo e a ideia de cultura da pobreza são divergentes e abrem possibilidades distintas de entender a questão. A última reforçava uma ideia comportamental, moral, de ação individual e mentalidade, enquanto o primeiro enfatiza mais projetos, programas e intervenções práticas no cotidiano das pessoas. O fato de Harrington cruzar os conceitos acriticamente reforçou o espaço dos elementos culturais e psicológicos naquele momento e contribuiu para o debate entre intelectuais e políticos responsáveis pelas políticas públicas da década de 1960.

A temática do welfare e do salário mínimo, muito presente entre os movimentos sociais,

28 Tradução minha. Original: The poor get sick more than anyone else in the society. That is because they live in slums, jammed together under unhygienic conditions; they have inadequate diets, and cannot get decent medical care. When they become sick, they are sick longer than any other group in the society. Because they are sick more often and longer than anyone else, they lose wages and work, and find it difficult to hold a steady job. And because of this, they cannot pay for good housing, for a nutritious diet, for doctors. 
também é abordada por Harrington. O autor critica o modelo de salário mínimo e de welfare americano, no sentido de terem se expandido sem atingir os mais necessitados. Similar as críticas de uma desigualdade desses benefícios na sociedade, Harrington acreditava que o salário mínimo deveria ser mais amplo e que o sistema de welfare funcionava melhor para quem não era tão necessitado (IDEM, Posição 784). Preocupado com o universo do subemprego e dos baixíssimos salários, salienta como os trabalhadores afro-americanos sofreram com o fechamento de postos em indústrias no contexto da transformação do mercado e da economia internacional, em um cenário de mercado de trabalho já desfavorável para as minorias. Com o fim de alguns setores na indústria, esses trabalhadores acabavam no universo do subemprego por não possuírem a qualificação necessária para postos equivalentes (IDEM). O ciclo da pobreza estaria manifesto nesses acontecimentos, ainda mais quando essas pessoas não conseguiam trabalho por ausência de educação e treinamento. A exclusão gerada pelo racismo era outro elemento nesse ciclo, tendo em vista que, segundo Harrington, trabalhadores brancos eram proporcionalmente melhores treinados e, quando não eram, conseguiam empregos com mais facilidade do que os afro-americanos.

A importância desses subempregos dentro do próprio mercado é observada pelo autor como uma estratégia. Para ele, o mercado se aproveitava de determinado tipo de trabalhador, em destaque mulheres e afro-americanos, para utilizá-los em algumas categorias de subempregos. As transformações na constituição familiar eram igualmente importantes para esse argumento. Essa discussão não é nenhuma novidade e aparece em inúmeros trabalhos que pensavam como a segregação era importante para manter os afro-americanos em postos inferiorizados dentro da sociedade. ${ }^{29}$ Contudo, é um indicador significativo das formas de compreender a pobreza. Como o aspecto psicológico era muito impactante para ele, associou a situação do mercado de trabalho com a humilhação sentida, em especial pelos homens ${ }^{30}$, com o subemprego, o desemprego e com o crescimento do emprego feminino, graças aos salários mais baixos.

No campo intelectual e político, Harrington repreendia o otimismo liberal como uma barreira para reconhecer a dimensão do racismo institucionalizado nos Estados Unidos, para além do Sul. Por isso, era necessário reconhecer os seus efeitos no Norte, a desigualdade de oportunidade, qualificação e emprego entre brancos e afro-americanos, que mesmo quando qualificados e formados em boas universidades, se viam restritos ao ambiente segregado presente em todo o país. A discussão de Harrington não era inédita, Du Bois já apontava o impacto institucional do racismo para pensar a pobreza em Philadelphia Negro, no começo do século. Ainda assim, a voz de Harrington, o público do autor e o sucesso de vendas de Other America, levou esse tipo de crítica para uma multiplicidade de pessoas na sociedade. Muitas não necessariamente familiares com o tema. É importante lembrar aqui o processo de invisibilidade que a pobreza sofria, um silêncio e até negação em relação ao racismo no Norte, o fato do público-alvo ser de pessoas "não-pobres" e como essa desigualdade de origem racial não era reconhecida de modo geral. Harrington contribuiu para a expansão do debate e de outras formas de entender a pobreza.

29 Sobre isso: MUHAMMAD,Khalil. The Condemnation of Blackness: Race, Crime, and the Making of Modern Urban America. Boston: Harvard University Press, 2011.; HARRIS,Curtis. Locked in the Poorhouse Cities Race and Poverty in the US. Maryland: Rowman \& Littlefield Publishers, 2000; Clark, R., Anderson, N. B., Clark, V. R., \& Williams, D. R. Racism as a Stressor for African Americans: A Biopsychosocial Model. American Psychologist, 54, p.805-816, 1999.

30 O tema da "emasculação" vai ser constante entre pensadores nesse momento. Pensando a família afroamericana, a ausência de uma figura masculina é um dos debates mais populares, associando a questão com a pobreza e a delinquência. O Relatório Moynihan se destacou como a principal publicação naquele momento e sofreu criticas profundas do movimento afro-americano desde após a sua divulgação. 
Por outro lado, sua interpretação da cultura da pobreza e defesa de uma reforma que precisava ser feita na estrutura geradora da pobreza e, possivelmente, nos próprios pobres, o aproximou de intelectuais e membros do governo Johnson responsáveis por pensar as políticas públicas da Guerra à Pobreza. O livro de Harrington expressava um sentimento de necessidade de transformação, presente naquele momento de diferentes maneiras: em políticos, intelectuais e movimentos sociais. Harrington produziu críticas mais profundas acerca da sociedade americana do que as postas em prática pelo Partido Democrata em 1960. Seu texto fez denúncias importantíssimas e atingiu uma camada da sociedade que não necessariamente compartilhava dessas preocupações. Simultaneamente, o livro possibilitou interpretações culturais da pobreza, reforçando certas interpretações daquela época.

\section{Conclusão}

A pobreza não era uma concepção homogênea. Seus nuances passavam pela ideia de deserving e undeserving, pela concepção do que era ser pobre em 1960 nos Estados Unidos, da sua dimensão naquele momento de crescimento da economia e dos fatores originários. O welfare tinha relação com as perspectivas sobre o problema. O que era welfare? Qual o seu propósito? Auxiliava ou corroborava com a pobreza? O país deveria investir em benefícios sociais? Qual a profundida de transformações esses benefícios deveriam trazer? O crescimento econômico norte-americano na década de 1940 transformou o cenário nacional. Antes assolada pela Depressão, o pauperismo parecia cada vez mais distante para boa parte da nação. Nesse período, a ilusão de que o progresso era quase absoluto se expandiu com o afastamento do imaginário coletivo instituído após a Crise de 1929. A pouca informação e divulgação de estudos sobre a questão corroborou nesse sentido. Se o país vivia uma suposta prosperidade em massa e não mais uma pobreza em massa, não haveria necessidade de ampliar os projetos do New Deal. Muito pelo contrário, entre 1940 e 1950 o New Deal sofreu inúmeros cortes.

O tema da pobreza ressurgiu enquanto a riqueza nacional era debatida. Em um país tão próspero, esta era a antítese do que os Estados Unidos deveriam significar simbolicamente para autores como Galbraith e Harrington. A persistência do problema era o "calcanhar de Aquiles" do projeto de florescimento, ascensão e consolidação do país enquanto uma nação abundante no imaginário nacional e internacional. Por essa razão, o governo Kennedy passou a estudar o objeto e buscar soluções práticas. Com a morte de Kennedy, o governo LBJ assumiu a tarefa de combater a pobreza através da Guerra à Pobreza entre 1964 e 1968. Durante esse período, o projeto foi palco ativo de debates que impactaram a formação e reformulação das políticas públicas desenhadas pelo governo. Reflexo das disputas políticas e do impasse sobre como executar o plano de eliminar a pobreza no país, a Guerra à Pobreza foi permeada por constantes modificações nos planejamentos e pelos desacordos administrativos no sentido de quem e como iria gerenciá-la. A falta de consenso em entender o tema marcou as políticas que tentavam solucioná-lo.

\section{Referências}

PATTERSON, James. America's Struggle Against Poverty in the Twentieth Century. Massachussetts: Harvard University Press, 2000.

PETERSON, P. "The Urban Underclass and the Poverty Paradox," Political Science Quarterly, 106, 1992, p.617-638. 
KATZ, Michael. The Undeserving Poor: America's Enduring Confrontation with Poverty . Oxford: Oxford University Press,2013. Versão Kindle.

KATZ, Michael. In the Shadow of the Poorhouse: A Social History of Welfare in America. Tenth Anniversary Edition. New York: Basic Books, 1996. Versão Kindle.

KATZNELSON, Ira. When Affirmative Action Was White: An Untold History of Racial Inequality in Twentieth-Century America. Nova York: W. W. Norton \& Company, 2015. Versão Kindle.

MYRDAL, Gunnar. An American dilemma: the Negro problem and modern democracy. New York: Pantheon Books, 1975.

DU BOIS, W.E.B. The Philadelphia Negro: A Social Study. Pensilvânia: University of Pennsylvania Press.1899

GALBRAITH, John Kenneth. The Affluent Society. Boston: Houghton Mifflin Company, 1958.

LEWIS, Oscar. Five Families: Mexican Case Studies in the Culture of Poverty. New York: Basic Books, 1959.

HARRINGTON, Michael. The Other America: Poverty in the United States. New York: Macmillan, 1962. Versão Kindle.

KATZ, Michael (Ed.) The "Underclass" Debate: Views from History. Nova Jersey: Princeton University Press, 1992.

WILSON, William. Truly Disadvantaged. Chicago: University of Chicago Press, 1987.

Artigo recebido em: 29/10/2019

Artigo aceito em: 10/12/2019 